\title{
Dog ownership and physical activity: A review of the evidence
}

Brief running title: Review of dog ownership and PA

Key words: Walking, Dog, Dog walking, Recreational activity, Meta-analysis

Abstract word count: 200

Main text word count: 26 pages; 4382 (excluding tables); 5464 with tables

Date of manuscript submission: 30 August 2011 


\section{Abstract}

\section{Background:}

3 Dog walking is a strategy for increasing population levels of physical activity (PA).

4 Numerous cross-sectional studies of the relationship between dog ownership and PA have

5 been conducted. The purpose was to review studies comparing PA of dog owners (DO) to

6 non-dog owners (NDO), summarize the prevalence of dog walking, and provide

7 recommendations for research.

\section{Methods:}

9 A review of published studies (1990-2010) examining DO and NDO PA and the prevalence

10 of dog walking was conducted $(\mathrm{N}=29)$. Studies estimating the relationship between dog

11 ownership and PA were grouped to create a point-estimate using meta-analysis.

\section{Results:}

13 Most studies were conducted in the last five years, were cross-sectional, and sampled adults

14 from Australia or the United States. Approximately $60 \%$ of DO walked their dog, with a

15 median duration and frequency of 160 minutes/week and 4 walks/week, respectively. Meta-

16 analysis showed DO engage in more walking and PA than NDO and the effect sizes are small

17 to moderate $(\mathrm{d}=0.26$ and $\mathrm{d}=0.16$ respectively). Three studies provided evidence of a

18 directional relationship between dog ownership and walking.

\section{Conclusions:}

20 Longitudinal and interventional studies would provide stronger causal evidence for the

21 relationship between dog ownership and PA. Improved knowledge of factors associated with

22 dog walking will guide intervention research. 


\section{Introduction}

26 Regular physical activity (PA) is important in the prevention of chronic disease ${ }^{1,2}$.

27 Nevertheless, a significant proportion of youth and adults do not meet the recommended level

28 of PA required for health benefits ${ }^{3-5}$. Walking is a popular form of PA because it is

29 considered easy and requires little skill or finances ${ }^{6,7}$.

30

31 Dog ownership may be associated with higher levels of PA ${ }^{8-11}$. In many developed countries

32 rates of dog ownership are high. For example, an estimated $39 \%$ of United States (US) ${ }^{12}$ and

$3340 \%$ of Australian ${ }^{13}$ households own at least one dog. This level of ownership illustrates the

34 strong level of attachment that exists between humans and canines. Considering the large

35 proportion of dog owners and that many dogs enjoy being walked, dog walking could provide

36 a potentially viable strategy for increasing population levels of PA.

37

38 Research on this topic is growing rapidly and its potential as a PA intervention strategy is

39 being recognized ${ }^{14}$. Therefore, a review of the evidence is timely. This paper (1) reviews

40 studies that compared PA of dog owners (DO) to non-dog owners (NDO) and (2) summarizes

41 the prevalence of dog walking from the scientific literature. Based on these findings, we

42 discuss recommendations to help advance the field of dog walking research.

43

\section{Methods}

\section{Search strategy}

46 Electronic databases were searched for relevant published articles (MEDLINE, PsychINFO,

47 FAMILY: Australian Family and Society abstracts, ProQuest social science journals,

48 ScienceDirect, Web of Science, and Academic Search Complete). Dog-related keywords

49 (dog, dog walking, dog ownership, canine, pet, pet ownership, companion animal, human 
50 animal interaction) were crossed with PA-related keywords (walking, PA, leisure-time PA,

51 leisure-time exercise, health, human health) for the search. The searches included only peer-

52 reviewed studies published in the English language between 1990 and 2010. Reference lists

53 from articles we included were also scanned and cross-referenced for additional potential

54 studies.

55

\section{Eligibility criteria}

57 Papers were excluded if the outcome measure was related to the health of the dog and not to

58 humans (Appendix). Reviews, reports, case reports, qualitative studies, and abstracts only

59 were excluded. Cross-sectional, surveillance, and cohort studies were included. Overall, 99

60 articles met the inclusion criteria. After excluding articles that did not report data comparing

61 DO and NDO PA or the prevalence of dog walking by owners, 29 articles were included in

62 the review. Among the cross-sectional studies, 11 studies reported on DO and NDO PA, nine

63 studies reported on the amount of dog walking by owners, and six studies reported on both

64 DO and NDO PA and the prevalence of dog walking by owners. In addition, three studies reported longitudinal data on the relationship between dog ownership and PA.

66

67 Meta-analysis

68 This systematic review provided the opportunity to conduct a meta-analysis and calculate a

69 summary estimate of the (1) walking and (2) PA levels, of DO compared with NDO. Studies

70 were included in the meta-analyses if they featured a relationship between a walking $(n=11$;

71 see Table 1) or PA ( $n=6$; see Table 1) variable and a dog ownership variable expressed in

72 terms of an effect size (r, OR, or d). The referent was NDO and the dependent variable was

73 minutes of walking or PA (when available). The meta value is subject to some variability

74 because studies used different metrics to measure the dependent variable, however, this was

75 overcome by using the standardized mean difference as the summary statistic. When multiple 
76 ORs were present due to sub-analyses, only the total sample effect size was used. Along with

77 the weighted average standardized mean difference, 95\% confidence intervals (CI) were

78 computed. Data were analyzed using Comprehensive Meta-analysis-2 software ${ }^{15}$.

79

80 The studies reviewed were grouped and analyzed using three main themes. First, a

81 descriptive analysis and a meta-analysis of studies of dog owner and non-dog owner walking

82

83

84

85

\section{Results}

87

88

89

90

91

92

93

94

95

96

97

98

99

100

Insert table 1 here 
102 Overall, adult DO reported more minutes per week of PA (median: DO=329; NDO=277)

103 and/or walking (median: $\mathrm{DO}=129 ; \mathrm{NDO}=111$ ) than NDO. Four of the fourteen studies

104 reported differences between DO and NDO PA using objective measures (i.e., accelerometer

105 and/or pedometer). Among these studies, two sampled children ${ }^{19,20}$, one sampled older adults

$10{ }^{18}$, and the other sampled adults ${ }^{22}$, however, all showed that DO had significantly higher

107 levels of objectively measured PA than NDO.

108

109 The point estimate for random effects meta-analysis was a standardized mean difference

110 between DO and NDO of 0.26 (95\% CI: $0.16,0.35)$ for walking and 0.16 (95\% CI: 0.03 ,

1110.30 ) for PA. Thus, DO walked more than NDO and were more physically active than NDO.

112 The effect can be categorized as a small to moderate yet meaningful difference.

113

114 Prevalence of dog walking

115 Table 2 summarizes 15 studies examining the amount of dog walking by DO (6 of these

116 studies are also included in Table 1). Studies were conducted between 2001 and 2010, the

117 majority either from Australia $(n=8)$ or the US $(n=6)$. Across the studies the mean sample

118 size was 4251 (range=24-47731) and median age of adult participants was 45 years (IQR:

$11937.0,55.3)$. Two of these studies sampled older, predominantly female adults ${ }^{18,23}$. Moreover,

120 two studies were conducted with the same sample of Australian children aged 5-6 and 10-12

121 years ${ }^{20,24}$ and three studies sampled different sub-groups from the same study ${ }^{25-27}$. Across

122 studies of middle-age adults $22-52 \%$ of the samples were male. Five studies included DO

123 only and the remainder either reported a dog ownership rate comparable to the population

124 rate of dog ownership within the country of the study $(n=7)$ or did not report the prevalence

125 of dog ownership in their sample $(n=3)$. 
130 The median prevalence of dog walking amongst DO across all studies was 59\% (range=3-

$13180 \%$ ). Ten studies provided descriptive data on duration and/or frequency of dog walking

132 (three studies provided both). Median duration and frequency of weekly dog walking

133 amongst studies sampling adults were 160 minutes (IQR: 114.6, 210.0) and 4 walks (IQR:

$1342.4,4.8$ ), respectively; this equates to approximately four walks per week of 40 minutes each.

135 Twelve percent of children aged 5-6 years and 18\% of children aged 10-12 years walked their

136 dog at least 3 times per week ${ }^{24}$. Across both age groups children walked their dog on average

137 1.7 times per week $(\mathrm{SD}=2.1)^{20}$.

138

139 Longitudinal evidence of relationship between dog ownership and physical activity

140 To date, three studies ${ }^{28-30}$ have examined the relationship between dog ownership and PA

141 using a longitudinal design.

142

143 In 1991, Serpell conducted a ten-month longitudinal study to examine changes in behavior

144 and health status of 71 adult subjects who recently acquired a pet from a UK animal shelter

145 (47 dog owners and 24 cat owners) ${ }^{28}$. Dog owners increased their recreational walking more

146 over a 10-month period compared to non-pet owners.

147

148 More recently, a US study by Thorpe and colleagues examined dog walking behavior of 394

149 DO and 2137 NDO and walking speed over three years in a sample of community-dwelling

150 older adults (range 71-82 years) ${ }^{29}$. At follow-up, dog walkers were twice as likely as non- 
151 dog walkers and NDO to achieve recommended walking levels, independent of demographic

152 factors and health-related characteristics. While dog walkers and NDO showed similar

153 declines in usual and rapid walking speed, dog walkers maintained their initial mobility

154 advantage ${ }^{29}$. Although dog ownership appeared to facilitate walking behavior, the prevalence

155 of dog ownership was low (15.5\%) and only a minority of older DO walked their dog (36\%).

156

157 Finally, an Australian study by Cutt and colleagues in $2008^{30}$ examined changes in socio-

158 demographic, environmental and intrapersonal factors associated with dog acquisition in

159 adult NDO at baseline to 12-months follow-up and the effect of dog acquisition on minutes

160 per week of recreational walking. At 12 months follow-up 12\% $(\mathrm{n}=92)$ of baseline NDO had

161 acquired a dog and 681 had remained NDO. After adjusting for baseline variables, the effect

162 of dog acquisition on the increase in minutes of neighborhood recreational walking was 31

163 minutes/week (95\% CI: 7.4, 54.2). However, this reduced to 22 minutes (95\% CI: -1.5, 45.4)

164 after further adjustment for change in baseline to follow-up variables. Increase in intention to

165 walk mediated the effect of dog acquisition on recreational walking ${ }^{30}$. Importantly, this study

166 measured change in dog ownership status over time and adjusted for both baseline and

167 change over time confounders.

168

\section{Discussion}

170 Overall, the results of this review indicate that dog ownership is consistently associated with

171 higher levels of walking and PA compared to those who do not own dogs. Moreover, DO

172 (and dog walkers) were more likely than NDO (and non-dog walkers) to meet the

173 recommended levels of $\mathrm{PA}^{2}$. The results of the meta-analyses showed that DO walk more

174 and are more physically active than NDO. These effects can be categorized as a small to

175 moderate yet meaningful difference and are an important first step at summarising this data. 
176 However, the analysis was limited due to variations in the metrics of the dependent variables

177 and study samples.

178

179 These findings, primarily from cross-sectional studies, are further strengthened by

180 longitudinal data; however, there is a paucity of longitudinal studies that contain measures of

181 dog ownership, dog walking or any other dog-related characteristics. For example, if

182 questions on dog ownership and dog walking behavior were regularly added to state and

183 national PA and or health surveys it could provide a potential source of longitudinal data that

184 would assist in determining the relationship between dog ownership, dog walking and PA.

185 Further, more research is required to confirm that getting a dog does in fact cause people to

186 walk more and whether the increase in walking as a result of acquiring and walking a dog is

187 at the expense of other types of PA (e.g., sport participation, transport-related trips) ${ }^{30}$.

188 Specifically, does dog acquisition influence changes in total PA, recreational walking,

189 transport-related walking, other moderate-intensity activity and high intensity activity over

190 the short and long term? Moreover, what impact does the long-term commitment of dog

191 ownership play in maintaining walking behavior?

192

193 The results of this review highlight a number of important methodological considerations for

194 future dog walking studies. While the scientific rigour of the studies presented has improved

195 over time, many studies do not adequately control for confounding factors. For example,

196 socio-demographic characteristics such as age, gender, socioeconomic status, and ethnicity

197 are known to be associated with health behaviors such as PA ${ }^{31,32}$ and are also associated with

198 dog ownership ${ }^{33}$ and thus should be tested as potential confounders in analyses exploring

199 associations between dog ownership and PA. 
201 Another methodological limitation observed during this review is the inconsistent use of

202 terminology. Regarding the definition of ownership, because increased PA of pet owners may

203 be due to dog walking, studies should specifically measure dog ownership rather than pet

204 ownership. Moreover, this review shows that many DO are not active with their dogs. Thus,

205 those that walk their dog should be distinguished from those that own a dog but do not walk

206 their dog. Furthermore, consistent terminology should be used to define different sub-groups

207 and it is recommended that researchers refer to dog owners (DO), non-dog owners (NDO),

208 dog walkers (DW), and those who do not walk with their dogs - non-dog walkers (NDW), as

209 appropriate and has been done in this paper. Finally, consistency in the outcome measures

210 reported would allow study results to be compared. Researchers should attempt to report

211 outcomes of total and leisure-time PA and walking in minutes per week, proportion meeting

212 recommended level of $\mathrm{PA}^{2}$, and for DO, prevalence of dog walking as well as minutes (and

213 frequency) of dog walking per week.

214

215 Only four studies in this review used an objective measure of PA (i.e., accelerometer or

216 pedometer) to compare the PA level of DO and NDO ${ }^{18-20,22}$. The results confirm our findings

217 of studies using self-report measures of PA. Future studies should include objective outcome

218 measures to supplement self-reported measures. In particular, a reliable and valid measure of

219 the amount of walking DO engage in with and without their dog is required. Studies have

220 used self-report measures of minutes and frequency of walking with a dog. However, time

221 actually spent being physically active with a dog may vary widely from standing in a park

222 whilst the dog investigates off lead, to ten mile jogs on lead. A recent study of dog behavior

223 on walks suggests that a significant proportion of the dog's walking time is actually spent

224 sniffing ${ }^{34}$, which may result in many stationary and very slow walking speeds for owners and

225 may also vary according to whether the dog is on or off-leash. Thus, it is recommended that 
226 future dog walking research objectively measures the duration, frequency, intensity and

227 patterns of walking done with a dog, the contribution this makes to their overall PA level, and

228 how the behavior of the dog (e.g., sniffing, chasing a ball, on/off leash) influences the

229 intensity and amount of walking that owners perform.

230

231 The results of this review stress the need for further dog walking studies to be conducted in

232 other countries. The majority of studies were from the US and Australia, one each from

233 Canada and Japan and although two studies were from the UK they did not examine a general

234 adult population. To our knowledge, no dog walking studies have been conducted in

235 developing countries and these studies may be important because the culture of dog-keeping

236 is likely to be different from populations examined so far. Furthermore, the results of this

237 review indicate that further studies of the relationship between dog ownership, dog walking

238 and PA needs to be conducted in children and adolescents, and in diverse ethno-racial and

239 socio-economic groups.

240

241 Despite shortcomings of the research to date, there is consistent correlational evidence for the

242 positive association between dog ownership and PA. To enable public health practitioners to

243 promote walking with the dog as an effective intervention tool to promote PA more research

244 is needed to understand the correlates, determinants and mediators of dog walking behavior.

245 Only five studies have examined the correlates of dog walking behavior ${ }^{25,27,35,36,37}$. While it

246 appears that owner's perceived motivation, obligation and social support provided by the dog

247 to walk are the most important factors associated with both not walking with a dog as well as

248 regularly walking with a $\operatorname{dog}^{25,27}$, further studies are warranted. The results of this review

249 showed that on average about half of all DO don't walk with their dog. Only one study to

250 date has examined the factors associated with not walking with a dog ${ }^{25}$. Thus, in order to 
251 develop successful interventions, we need a better understanding of why these DO don't walk

252 their dog and how we can encourage them to do so. Finally, context specific measures of the

253 correlates as well as the behavior being examined are necessary in order to identify effective

254 strategies for intervention ${ }^{38,39}$

255

256 Summary of recommendations for future dog walking research:

257 - Consistently define and use dependent variables (mean minutes of PA, walking and

258 walking with dog, sufficient PA) and independent variables (DO; NDO; dog walker

259 (DW); and non-dog walker (NDW))

260 - Objectively measured PA (i.e., accelerometers or pedometers) in addition to self-

261 report measures

262

- Use context-specific measures

263 - Examine and adjust for confounders in analyses

$264 \quad$ Conduct more international studies

265

- Conduct more studies involving children and adolescents, race/ethnicity and socio-

266 economic groups

267 Conduct more longitudinal studies to elucidate determinants of dog walking behavior and mediators between dog ownership and walking

- Implement controlled intervention-based research to increase dog walking amongst

270 DO

- Initiate inter-disciplinary research and collaboration between researchers from the field of human and veterinary public health, animal behavior, and urban planning.

- Be informed of current activity in the area of dog walking research (Become a member of the International Dog Walking Activity Group (ID-WAG)) ${ }^{1}$.

\footnotetext{
${ }^{1}$ To become a member of ID-WAG contact Jackie Epping (jge5@cdc.gov)
} 
276 Conclusions

277 This review summarizes studies comparing the PA behavior of DO and NDO and the

278 prevalence of dog walking behavior. Overall, the findings suggest that dog walking research

279 needs to move beyond cross-sectional analyses of the PA levels of DO and NDO, to study

280 designs that will provide further evidence of the directional relationship between dog

281 ownership and PA. While dog walking has significant potential to increase the proportion of

282 the community who are physically active, either by encouraging those who do not walk their

283 dog to do so, or by increasing the amount of walking owners do with their dog, more research

284 is required to better understand the correlates, determinants, and mediators of dog walking

285 behavior. Improved knowledge of the factors associated with dog walking behavior will help

286 guide future dog walking intervention research. Moreover, significant progression of this

287 field requires more rigorous and consistent methodology as well as an interdisciplinary

288 approach.

\section{Author's contributions}

291 All authors contributed to the study conception and design, revised the manuscript critically

292 for intellectual content and approved the final version to be published. $\mathrm{HC}$ also analyzed the

293 data, interpreted the data, results and implications of the study and drafted the manuscript

294 revising it critically for important intellectual content at each stage. CW assisted with

295 identifying studies for inclusion, checked and interpreted the data, and substantially

296 contributed to drafting and revision of the manuscript. AB was involved with conceptualizing

297 the review, conducting the initial draft and reading and reviewing all manuscript drafts. LR 
298

299

300

\section{1}

302

303

304

305

\section{Acknowledgements}

307 The first author (Hayley Christian) is supported by a NHMRC Population Health Capacity

308 Building Grant (\#458668) and industry partner - Petcare Information and Advisory Service.

309 Carri Westgarth is supported by a UK Medical Research Council Population Health Scientist

310 Fellowship. Lori Horne and Lizette Grey (University of Victoria, Canada) are gratefully

311 acknowledged for their collation of studies for the meta-analysis. The authors acknowledge

312 Ms Rosanne Barnes, Ms Claire Evans and Ms Estee Lambin (The University of Western

313 Australia) for their administrative assistance.

314

\section{Funding source/trial registration}

316 This research did not receive external funding. 
1. WHO. The World Health Report: Reducing risks to health, promoting healthy life. World Health Organisation, Geneva; 2002.

2. U.S. Department of Health and Human Services. U.S. National Physical Activity Plan. U.S. Department of Health and Human Services, Washington D.C.; 2008.

3. Carlson S, Fulton J, Galuska D, Kruger J, Lobelo F, Loustalot F. Prevalence of selfreported physically active adults-United States, 2007. Morb Mortal Wkly Rep. 2008;5748:1297-1300.

4. Chau J. Trends in Population Levels of Sufficient Physical Activity in NSW, 1998-2005: Full Report. NSW Centre for Physical Activity and Health, University of Sydney, Australia; 2007.

5. U.K. Department of Health. At Least Five a Week: Evidence on the impact of physical activity and its relationship to health. A Report from the Chief Medical Officer. U.K. Department of Health, London; 2004.

6. Owen CG. Understanding enviornmental influences on walking. Am J Prev Med. 2004;271:67-76.

7. Dunton GF. Perceived barriers to walking for physical activity. Prev Chronic Dis. 2006;34.

8. Cutt H, Giles-Corti B, Knuiman M, Burke V. Dog ownership, health and physical activity: A critical review of the literature. Health Place. 2007;13:261-272.

9. Jennings LB. Potential benefits of pet ownership in health promotion. J Holistic Nurs. 1997; 154:358-372.

10. Allen DT. Effects of dogs on human health. JAVMA. 1997;210:1136-1139.

11. Katcher AH. Physiologic and behavioural responses to companion animals. Vet Clin North Am Small Anim Prac. 1985;152:403-410.

12. American Pet Products Manufacturers Association. American Pet Products Manufacturers Association 2009-2010 National Pet Owners Survey. http://www.humanesociety.org/issues/pet_overpopulation/facts/pet_ownership_statistics. html; 2010; Accessed 24 March 2010.

13. Australian Companion Animal Council Inc. Australian Companion Animal Council Inc Pet ownership statistics. http://www.acac.org.au/pet_care.html; 2010; Accessed 24 March 2010.

14. Johnson RA. Dog-walking: Motivation for adherence to a walking program. Clinl Nurs Res. 2010;194:387-402.

15. Biostat. Comprehensive Meta-analysis. Englewood, New Jersey; 2006.

16. Thorpe RJ, Kreisle RA, Glickman LT, Simonsick EM, Newman AB, Kritchevsky S. Physical activity and pet ownership in year 3 of the Health ABC Study. J Aging Phys Activ. 2006;14:154-168.

17. Dembicki D, Anderson J. Pet ownership may be a factor in improved health of the elderly. J Nutr Elderly. 1996;153:15-31.

18. Harris TJ, Owen CG, Victor CR, Adams R, Cook DG. What factors are associated with physical activity in older people, assessed objectively by accelerometry? Br J Sports Med. 2009;436:442-450.

19. Owen CG, Nightingale CM, Rudnicka AR, et al. Family dog ownership and levels of physical activity in childhood: Findings from the Child Heart and Health Study in England. Am J Pub Health. 2010;1009:1669.

20. Salmon J, Binh Chu AT and Veitch J. Dog ownership, dog walking, and children's and parents' physical activity. Res Q Exercise Sport. 2010;813:264-271. 
21. Ball K, Timperio A, Salmon J, Giles-Corti B, Roberts R, Crawford D. Personal, social and environmental determinants of socioeconomic inequalities in walking: A multilevel study. J Epidemiol Comm Health. 2007;61:108-114.

22. Coleman KJ, Rosenberg DE, Conway TL, et al. Physical activity, weight status, and neighborhood characteristics of dog walkers. Prev Med. 2008;473:309-312.

23. Johnson RA, Meadows RL. Older latinos, pets, and health. West J Nurs Res. 2002;246:609-620.

24. Timperio A, Salmon J, Chu B, Andrianopoulos N. Is dog ownership or dog walking associated with weight status in children and their parents? Health Promot J Aust. 2008;191:60.

25. Cutt H, Giles-Corti B, Knuiman M. Encouraging physical activity through dog walking: Why don't some dog owners walk with their dog? Prev Med. 2008;46:120-126.

26. Cutt H, Giles-Corti B, Knuiman M, Timperio A, Bull F. Understanding dog owners' increased levels of physical activity: Results from RESIDE. Am J Pub Health. 2008;981:66-69.

27. Christian (nee Cutt) H, Giles-Corti B, Knuiman M. "I'm just a'-walking the dog" Correlates of regular dog walking. Fam Comm Health. 2010;331:44-52.

28. Serpell J. Beneficial effects of pet ownership on some aspects of human health and behavior. J Roy Soc Med. 1991;84:717-720.

29. Thorpe RJ, Simonsick EM, Brach JS, et al. Dog ownership, walking behavior, and maintained mobility in late life. J Am Geriatr Soc. 2006;doi:10.1111/j.15325415.2006.00856.x:electronic.

30. Cutt H, Knuiman M, Giles-Corti B. Does getting a dog increase recreational walking? Int J Behav Nutr Phys Act. 2008;5:17.

31. Conner M, Norman P. Predicting Health Behaviour: A Social Cognition Approach. In: Conner M, Ed. Predicting Health Behaviour. 2nd ed. Berkshire: McGraw-Hill Education; 2005:1-21.

32. Marmot M. Fair Society, Healthy Lives: The Marmot Review Executive Summary: The Marmot Review; 2010.

33. Westgarth C, Heron J, Ness AR, et al. Pet ownership during childhood: findings from a UK birth cohort and implications for public health research. Int J Environ Res Pub Health. 2010; 7:3704-3729.

34. Westgarth C, Christley RM, Pinchbeck GL, Gaskell RM, Dawson S, Bradshaw JWS. Dog behaviour on walks and the effect of use of the leash. Appl Anim Behav Sci. 2010:12512:38-46.

35. Rohlf VI, Toukhsati S, Coleman GJ, Bennett PC. Dog obesity: Can dog caregivers' (owners') feeding and exercise intentions and behaviors be predicted from attitudes? $J$ Appl Anim Welf Sci. 2010;133:213-236.

36. Brown SG, Rhodes RE. Relationship among dog ownership and leisure-time walking in western Canadian adults. Am J Prev Med. 2006;302:131-136.

37. Hoerster KD, Mayer JA, Sallis JF, et al. Dog walking: Its association with physical activity guideline adherence and its correlates Prev Med. 2010 E-pub.

38. Giles-Corti B, Timperio A, Bull F, Pikora T. Understanding physical activity environmental correlates: Increased specificity for ecological models. Exerc Sport Sci Rev.2005;33:175-181.

39. Giles-Corti B. People or places: What should be the target? J Sci Med Sport. 2006;95:357-366.

40. Headey B. Health benefits and health cost savings due to pets: preliminary estimates from an Australian national survey. Soc Indic Res. 1999;47:233-243. 
41. Bauman AE, Russell SJ, Furber SE, Dobson AJ. The epidemiology of dog walking: An unmet need for human and canine health. Med J Aust. 2001;175:632-634.

42. Giles-Corti B, Donovan RJ. Relative influences of individual, social-environmental, and physical environmental correlates of walking. Am J Pub Health. 2003;93:1583-1589.

43. Schofield G, Mummery K, Steele R. Dog ownership and human health-related physical activity: An epidemiological study. Health Prom J Aust. 2005;161:15-19.

44. Moudon AV, Lee $\mathrm{C}$, Cheadle $\mathrm{AD}$, et al. Attributes of environments supporting walking. Am J Health Prom. 2007;215:448-459.

45. Yabroff KR, Troiano RP, Berrigan D. Walking the dog: Is pet ownership associated with physical activity in California? J Phys Act Health. 2008;52:216-228.

46. Oka K, Shibata A. Dog ownership and health-related physical activity among Japanese adults. J Phys Act Health. 2009;64:412-418.

47. Gillum RF, Obisesan TO. Living with companion animals, physical activity and mortality in a U.S. national cohort. Int J Environ Res Pub Health.2010;76:2452-2459.

48. Suminski RR, Poston WSC, Petosa RL, Stevens E, Katzenmoyer LM. Features of the neighborhood environment and walking by U.S. adults. Am J Prev Med. 2005;282:149155.

49. Ham SA, Epping J. Dog walking and physical activity in the United States. Prev Chronic Dis Pub Health Res Pract Policy. 2006;3:1-7.

50. Tudor-Locke C, Ham SA. Walking behaviors reported in the American Time Use Survey 2003-2005. J Phys Act Health. 2008;55:633-647.

51. Merom $D$, Bowles $H$, Bauman $A$. Measuring walking for physical activity surveillance: The effect of prompts and respondents' interpretation of walking in a leisure-time survey. J Phys Act Health. 2008;55:633-647. 


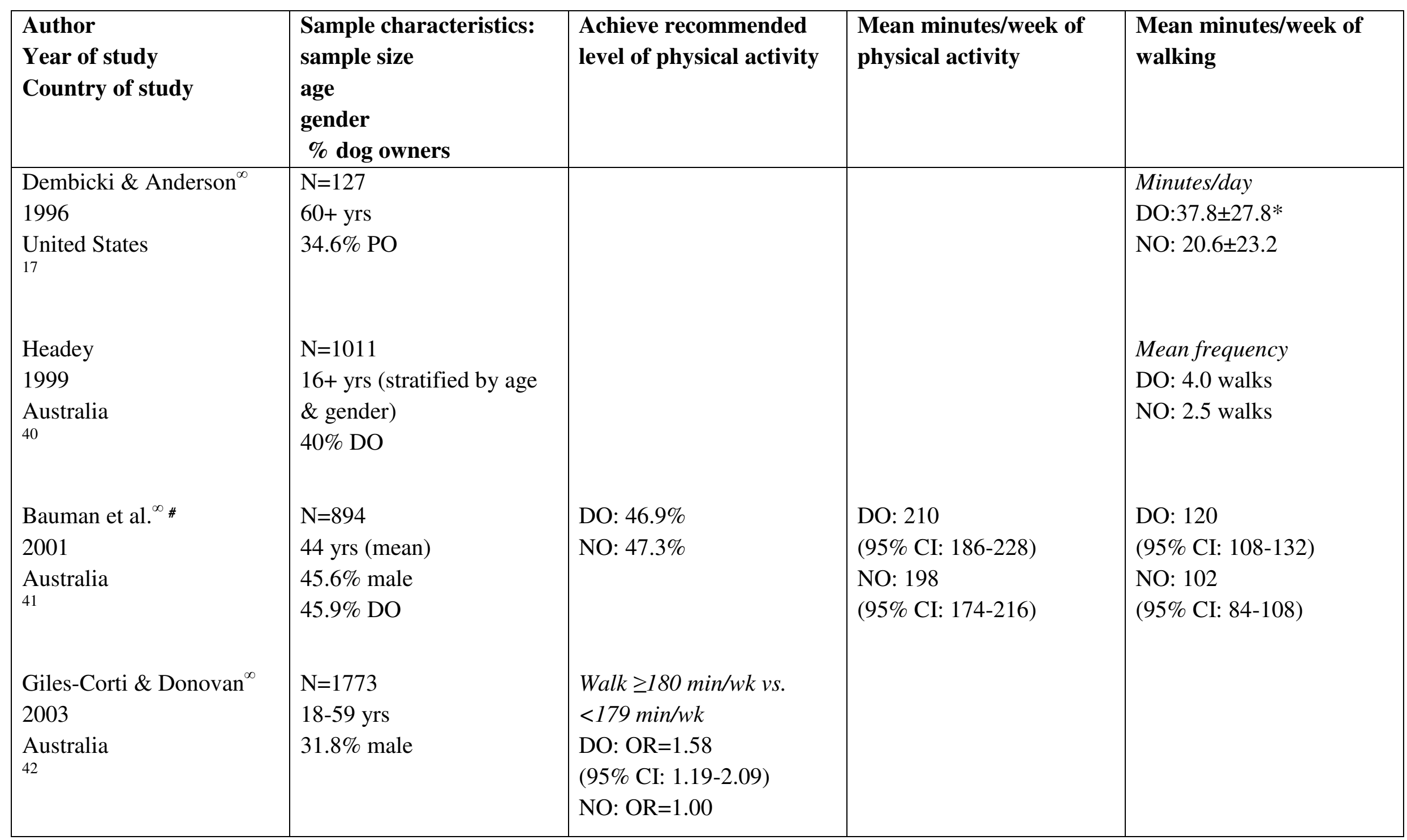


Review of dog ownership and PA

\begin{tabular}{|c|c|c|c|c|}
\hline $\begin{array}{l}\text { Schofield et al. }{ }^{\infty} \\
2005 \\
\text { Australia } \\
43\end{array}$ & $\begin{array}{l}\mathrm{N}=1237 \\
18+\text { yrs (stratified by age } \\
\& \text { gender) } \\
57.2 \% \text { DO }\end{array}$ & $\begin{array}{l}\text { DO: } 51.5 \% \\
\text { NO: } 48.5 \%\end{array}$ & $\begin{array}{l}\text { DO: } 334.8 \\
\text { NO: } 346.4\end{array}$ & $\begin{array}{l}\text { Walking for leisure } \\
\text { DO: } 114.9 \\
\text { NO: } 108.2\end{array}$ \\
\hline $\begin{array}{l}\text { Brown \& Rhodes } \\
2006 \\
\text { Canada } \\
36\end{array}$ & $\begin{array}{l}\mathrm{N}=351 \\
56 \text { yrs (mean for men) } \\
50.4 \% \text { male } \\
19.9 \% \text { DO }\end{array}$ & & $\begin{array}{l}\text { DO: } 410.3^{* *} \\
\text { NO: } 287.5\end{array}$ & $\begin{array}{l}\text { DO: } 300.2^{* *} \\
\text { NO: } 168.4\end{array}$ \\
\hline $\begin{array}{l}\text { Thorpe et al. } \\
2006 \\
\text { United States } \\
16 \\
\text { Ball et al. }{ }^{\infty} \\
2007 \\
\text { Australia } \\
21\end{array}$ & $\begin{array}{l}\mathrm{N}=2533 \\
70-79 \text { yrs } \\
48.3 \% \text { male } \\
12.9 \% \text { DO } \\
\\
\mathrm{N}=1282 \\
42 \text { yrs (mean) } \\
100 \% \text { female } \\
40 \% \text { DO }\end{array}$ & $\begin{array}{l}\text { Any physical activity } \\
\text { DO: } 67.2 \% \\
\text { NO: } 56.6 \% \\
\text { NPO: } 64.0 \% \\
\text { DO: OR }=1.32 \\
\text { (95\% CI: } 1-1.76 \text { ) } \\
\text { NO: OR=0.57 } \\
\text { (95\% CI: } 0.4-0.82) \\
\text { NPO: OR }=1.00 \\
\text { Any walking for leisure } \\
\text { DO: } 73 \% * \\
\text { NO: } 61 \%\end{array}$ & & $\begin{array}{l}\text { Non-exercise walking } \\
\text { DO: } 67.9^{*} \\
\text { NO: } 32.1 \\
\text { Exercise walking } \\
\text { DO: } 75.4 \\
\text { NO: } 57.8\end{array}$ \\
\hline
\end{tabular}


Review of dog ownership and PA

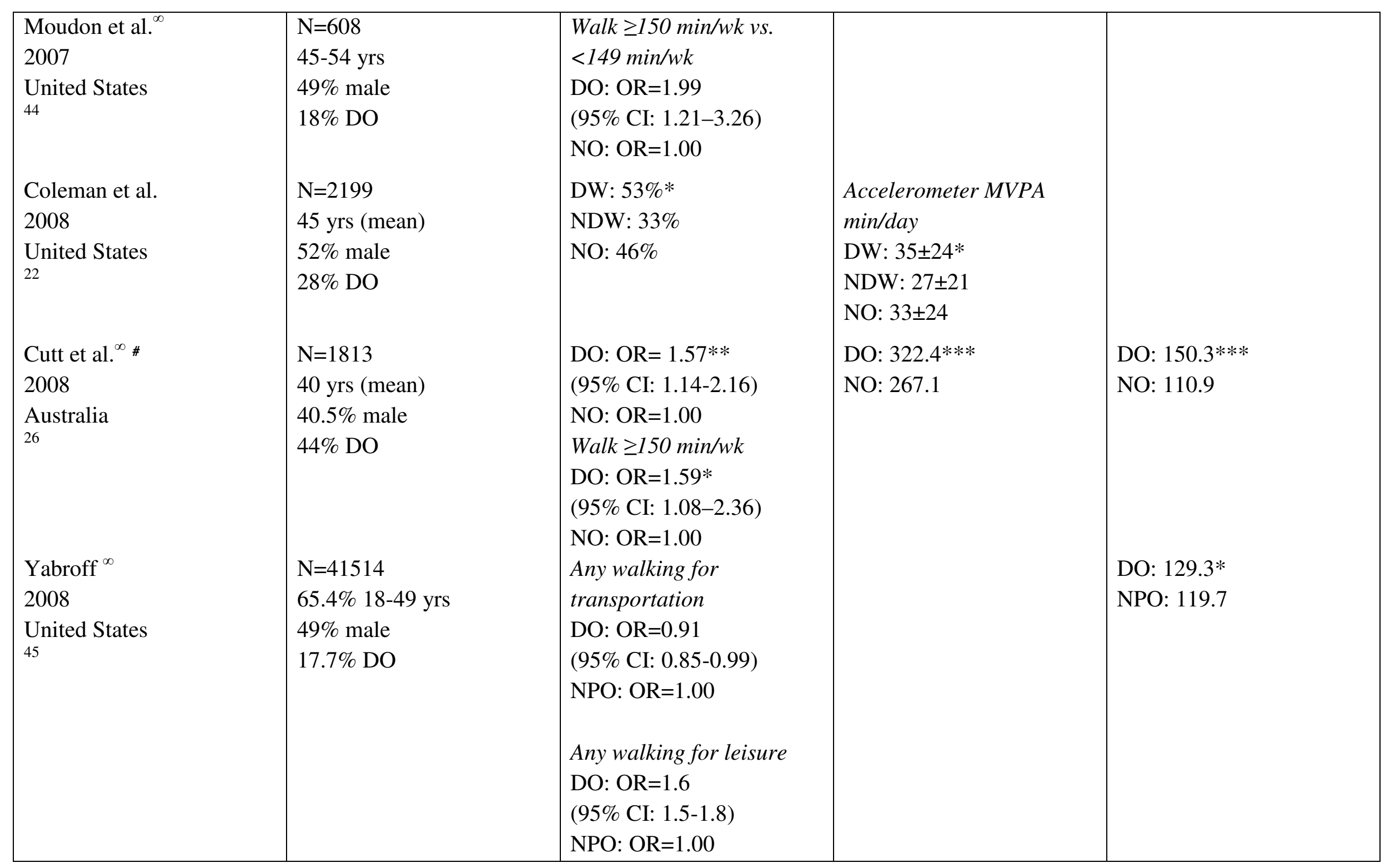




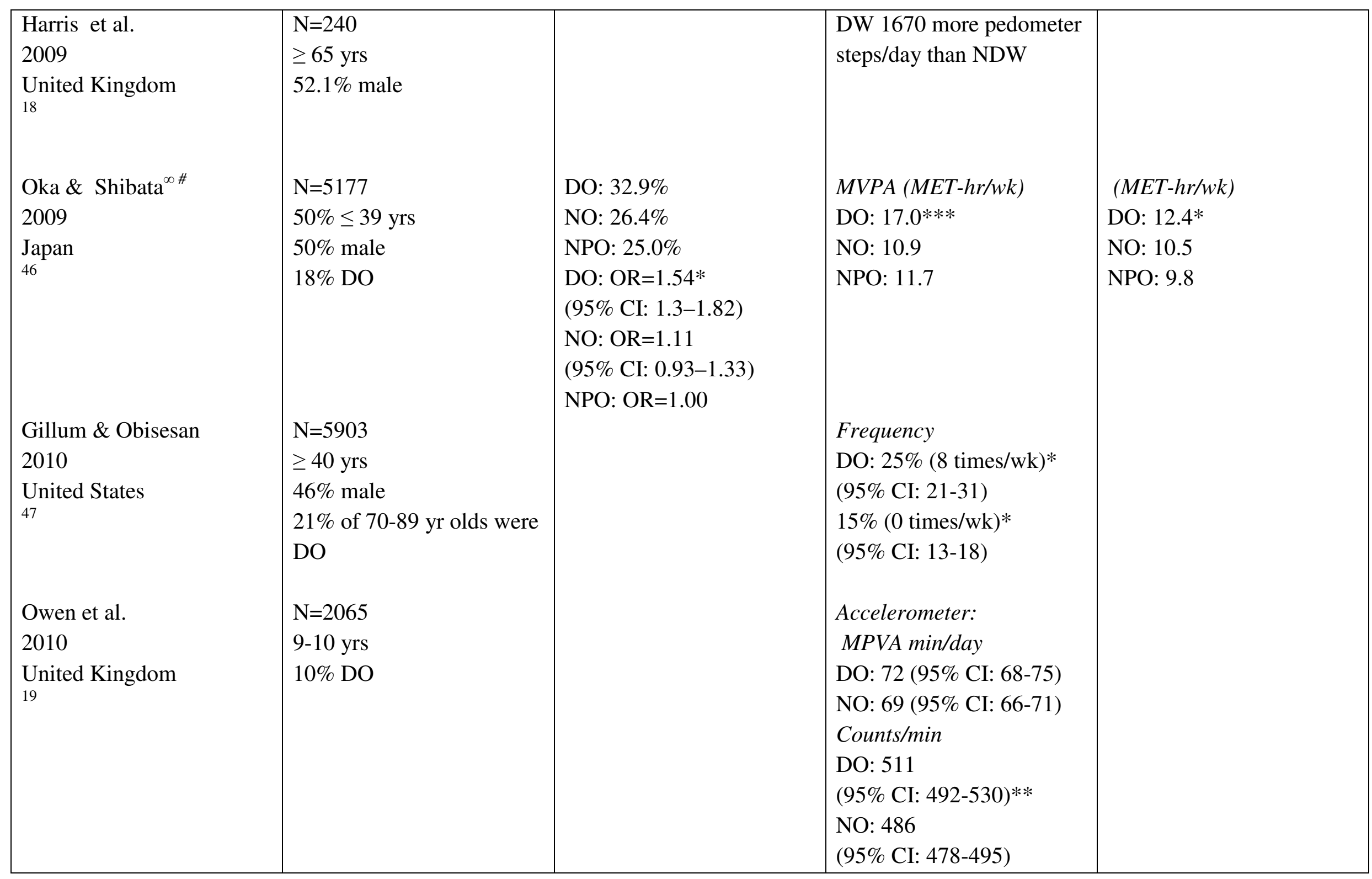




\begin{tabular}{|c|c|c|c|}
\hline $\begin{array}{l}\text { Salmon et al. } \\
2010 \\
\text { Australia } \\
20\end{array}$ & $\begin{array}{l}\mathrm{N}=294(5-6 \mathrm{yrs}) \\
\mathrm{N}=926(10-12 \mathrm{yrs}) \\
47.4 \% \text { boys } \\
44 \% \text { DO }(5-6 \mathrm{yrs}) \\
56 \% \text { DO }(10-12 \mathrm{yrs}) \\
\mathrm{N}=1152 \text { mothers } \\
\mathrm{N}=957 \text { fathers } \\
40 \text { yrs (mean) } \\
53 \% \text { DO }\end{array}$ & $\begin{array}{l}\text { NO vs. DO (total sample): } \\
\beta=-0.04 \\
(95 \% \mathrm{CI}:-0.45-0.38) \\
5-6 \text { yrs girls: } \\
\text { DO=29.3min/day more } \\
\text { accelerometer measured } \\
\text { MVPA (95\% CI: 5.5-53.1) } \\
\text { than NO }\end{array}$ & $\begin{array}{l}\text { NO vs. DO (total sample): } \\
\beta=-0.35 \\
(95 \% \text { CI: } 0.17-0.56)^{* * *} \\
10-12 \text { yrs girls: } \\
\text { DO=1.5 sessions/week } \\
\text { more than NO }\end{array}$ \\
\hline
\end{tabular}

${ }^{\infty}$ Indicates 11 studies included in the walking meta-analysis; ${ }^{\#}$ Indicates 6 studies included in the PA meta-analysis

$D O=$ dog owner; $N O=$ Non-dog owner; $D W=$ dog walker; $N D W=$ non-dog walker; $P O=$ pet owner; $N P O=$ non-pet owner

MVPA=Moderate Vigorous Physical Activity; METs- $h / w k=$ Metabolic equivalents hours/week

$* P<0.05 ; * * P<0.01 ; * P<0.001 ; N=$ sample size; OR=odds ratio; $95 \% C I=95 \%$ confidence interval; $\beta=$ linear regression $B$ coefficient 
Table 2: Prevalence of dog walking in publication date order (1996-2010)

\begin{tabular}{|c|c|c|c|c|}
\hline $\begin{array}{l}\text { Author } \\
\text { Year of study } \\
\text { Country of study }\end{array}$ & $\begin{array}{l}\text { Sample characteristics: } \\
\text { sample size } \\
\text { age } \\
\text { gender } \\
\% \text { dog owners }\end{array}$ & $\begin{array}{l}\text { Prevalence of dog } \\
\text { walking }(\%)\end{array}$ & $\begin{array}{l}\text { Minutes/week of dog } \\
\text { walking }\end{array}$ & $\begin{array}{l}\text { Frequency/week of dog } \\
\text { walking }\end{array}$ \\
\hline $\begin{array}{l}\text { Bauman et al. } \\
2001 \\
\text { Australia } \\
41\end{array}$ & $\begin{array}{l}\mathrm{N}=894 \\
44 \text { yrs (mean) } \\
45.6 \% \text { male } \\
45.9 \% \text { DO }\end{array}$ & 41.0 & 57 (mean) & 3 (median) \\
\hline $\begin{array}{l}\text { Johnson \& Meadows } \\
2002 \\
\text { United States } \\
23\end{array}$ & $\begin{array}{l}\mathrm{N}=24 \\
66 \text { yrs (mean) } \\
16.7 \% \text { male } \\
100 \% \text { DO }\end{array}$ & 45.8 & & 4 (mean) \\
\hline $\begin{array}{l}\text { Schofield et al. } \\
2005 \\
\text { Australia } \\
43\end{array}$ & $\begin{array}{l}\mathrm{N}=1237 \\
57.2 \% \mathrm{DO}\end{array}$ & $\begin{array}{l}\text { By a household } \\
\text { member } \\
60\end{array}$ & $\begin{array}{l}\text { Duration/session } \\
30 \text { (mode) }\end{array}$ & $\begin{array}{l}\text { By a household member } \\
7 \text { (mode) }\end{array}$ \\
\hline $\begin{array}{l}\text { Suminski et al. } \\
2005 \\
\text { United States } \\
48\end{array}$ & $\begin{array}{l}\mathrm{N}=474 \\
37 \text { yrs (mean) } \\
43.9 \% \text { male } \\
45.4 \% \text { DO }\end{array}$ & 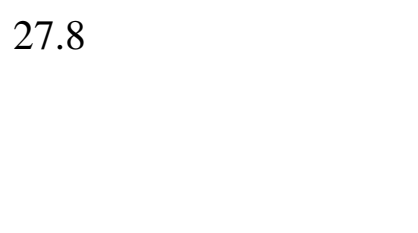 & & \\
\hline $\begin{array}{l}\text { Ham \& Epping } \\
2006 \\
\text { United States } \\
49\end{array}$ & $\begin{array}{l}\mathrm{N}=1282 \\
55.4 \% \geq 45 \mathrm{yrs} \\
41 \% \text { male } \\
100 \% \text { DO }\end{array}$ & $\begin{array}{l}\text { Daily dog walking of at } \\
\text { least } 10 \text { mins } \\
80.2\end{array}$ & $42.3 \% \geq 30 \mathrm{~min} /$ day & \\
\hline $\begin{array}{l}\text { Coleman et al. } \\
2008\end{array}$ & $\begin{array}{l}\mathrm{N}=2199 \\
45 \text { yrs (mean) }\end{array}$ & 70 & $\begin{array}{l}\text { Of those who walked } \\
180 \pm 186 \text { (mean) }\end{array}$ & \\
\hline
\end{tabular}


Review of dog ownership and PA

\begin{tabular}{|c|c|c|c|c|}
\hline $\begin{array}{l}\text { United States } \\
22\end{array}$ & $\begin{array}{l}52 \% \text { male } \\
28 \% \text { DO }\end{array}$ & & & \\
\hline Cutt et al. & $\mathrm{N}=1813$ & 78 & & 2.6 (mean) \\
\hline 2008 & 40 yrs (mean) & & & \\
\hline${ }_{26}^{\text {Australia }}$ & $40.5 \%$ male & & & \\
\hline Cutt et al. & $\mathrm{N}=629$ & 77 & 133.8 (mean) (SD: 112.8) & 4 (mean) (SD: 2.8) \\
\hline 2008 & $18+\mathrm{yrs}$ & & & \\
\hline $\begin{array}{l}\text { Australia } \\
25\end{array}$ & $100 \%$ DO & & & \\
\hline Timperio et al. & $\mathrm{N}=281(5-6 \mathrm{yrs})$ & $22.6(5-6 \mathrm{yrs})$ & & 5-6 yrs: \\
\hline 2008 & $\mathrm{~N}=864(10-12 \mathrm{yrs})$ & $36.9(10-12 \mathrm{yrs})$ & & $1-2$ times $/ \mathrm{wk}=10.6 \%$ \\
\hline Australia & $44.8 \%$ DO (5-6 yrs) & & & $\geq 3$ times $/ w k=12 \%$ \\
\hline & $57.3 \%$ DO (10-12 yrs) & & & 10-12 yrs: \\
\hline & & & & $\begin{array}{l}1-2 \text { times } / w k=18.7 \% \\
\geq 3 \text { times } / w k=18.2 \%\end{array}$ \\
\hline Tudor-Locke \& Ham & $\mathrm{N}=47731$ person-days & $2.6(2.3-2.8) \mathrm{dog}$ & Duration/day & \\
\hline 2008 & $31.9 \% 30-44 \mathrm{yrs}$ & walked in a 24 hour & 30 (median) & \\
\hline $\begin{array}{l}\text { United States } \\
50\end{array}$ & $43.5 \%$ male & period & & \\
\hline Harris et al. & $\mathrm{N}=240$ & 21.6 & & \\
\hline 2009 & $\geq 65 \mathrm{yrs}$ & & & \\
\hline $\begin{array}{l}\text { United Kingdom } \\
18\end{array}$ & $52.1 \%$ male & & & \\
\hline Merom et al. & $\mathrm{N}=3415$ & Of those who walk & & \\
\hline 2009 & $30.7 \% 30-44 \mathrm{yrs}$ & 13.2 (prompted & & \\
\hline$\underset{51}{\text { Australia }}$ & $43.9 \%$ male & response) & & \\
\hline
\end{tabular}


Review of dog ownership and PA

\begin{tabular}{|c|c|c|c|c|}
\hline $\begin{array}{l}\text { Christian (nee Cutt) et al. } \\
2010 \\
\text { Australia } \\
27 \\
\text { Salmon et al. } \\
\text { (2010) } \\
\text { Australia } \\
20 \\
\text { Hoerster et al. } \\
\text { (2010) } \\
\text { United States } \\
37\end{array}$ & $\begin{array}{l}\mathrm{N}=483 \\
\geq 18 \mathrm{yrs} \\
100 \% \text { DO } \\
\mathrm{N}=294(5-6 \mathrm{yrs}) \\
\mathrm{N}=926(10-12 \mathrm{yrs}) \\
47.4 \% \text { boys } \\
44 \% \text { DO (5-6 yrs) } \\
56 \% \text { DO (10-12 yrs) } \\
\mathrm{N}=1152 \text { mothers } \\
\mathrm{N}=957 \text { fathers } \\
40 \text { yrs (mean) } \\
53 \% \text { DO } \\
\mathrm{N}=984 \\
52 \text { yrs (mean) } \\
22.2 \% \text { male } \\
100 \% \text { DO }\end{array}$ & $\begin{array}{l}100 \\
59.0\end{array}$ & $\begin{array}{l}\text { Regular dog walkers: } \\
192.9 \text { (mean) (SD: 112.6)** } \\
\text { Irregular dog walkers: } \\
48.0 \text { (mean) (SD: 19.1) } \\
139.9 \text { (mean) (SD:181.3) }\end{array}$ & $\begin{array}{l}\text { Regular dog walkers: } \\
5.3 \text { (mean) (SD: 2.9)** } \\
\text { Irregular dog walkers: } \\
2.1 \text { (mean) (SD: } 1.3 \text { ) } \\
1.7 \text { (mean) (SD: } 2.1)\end{array}$ \\
\hline
\end{tabular}

$D O=$ dog owner; $N=$ sample size; $S D=$ Standard Deviation; $* P<0.05 ; * * P<0.01 ; * * P<0.001$ 


\title{
Appendix:
}

\author{
Search of electro nic datab ases: \\ -MEDLINE \\ -Pychl NFO \\ -FAMILY: Australian Fam ily andSociety abstracts \\ -ProQuest social science joumals \\ -Sience Diret \\ -Web of Science \\ -Aca detu ic SearchComplete \\ Limits: Enditish language, peer-reviewed, published 1990 - 2010
}

Key wonds AND combinations :

$\begin{array}{ll}\text { Dog related: } & \text { Physical activ ity rela ted: } \\ \text {-Dog } & \text {-Walking } \\ \text {-Dogwalking } & \text {-Physical activity } \\ \text {-Dog ownership } & \text {-Leiaute-titt e physical activity } \\ \text {-Canine } & \text {-Leisure-time ex ercise } \\ \text {-Pet } & \text {-H ealth } \\ \text {-Pet owner ship } & \text {-Hum an health } \\ \text {-Companion anith al } & \\ \text {-Hum an anim al interaction } & \end{array}$

Result: 109 (d uplicates removed)

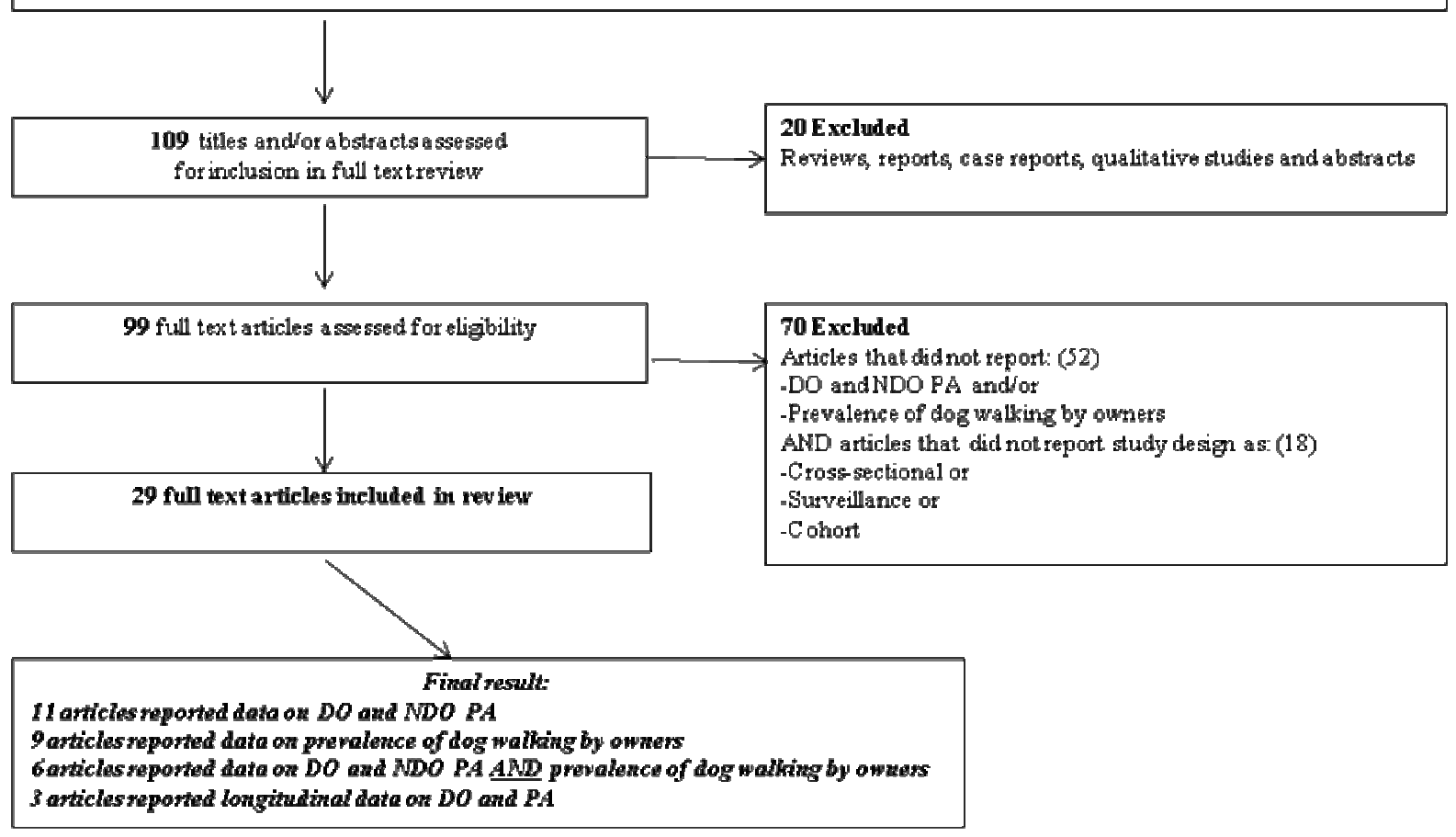

Figure1: Literature Search Strategy 